\title{
Finite Element Analysis and Vibration Control of a Deep Composite Cylindrical Shell Using MFC Actuators
}

\author{
Gangolu Vijay Kumar, ${ }^{1}$ Samikkannu Raja, ${ }^{2}$ \\ Karavadappa Basavarajappa Prasanna, ${ }^{2}$ and Valliappan Sudha ${ }^{2}$ \\ ${ }^{1}$ Mechanical Engineering Department, PVP Siddhartha Institute of Technology, Kanuru, Vijayawada 520007, Andhra Pradesh, India \\ ${ }^{2}$ Structural Technologies Division, National Aerospace Laboratories, Bangalore 560017, India \\ Correspondence should be addressed to Samikkannu Raja, raja@nal.res.in
}

Received 29 November 2011; Revised 25 January 2012; Accepted 3 February 2012

Academic Editor: Osama J. Aldraihem

Copyright ( 2012 Gangolu Vijay Kumar et al. This is an open access article distributed under the Creative Commons Attribution License, which permits unrestricted use, distribution, and reproduction in any medium, provided the original work is properly cited.

\begin{abstract}
A four-node composite facet-shell element is developed, accounting for electromechanical coupling of Macrofiber Composite (MFC) and conventional PZT patches. Further a warping correction is included in order to capture correctly the induced strain of conformable MFC, surface bonded on a cylindrical shell. The element performance to model the relations between in-plane electric field to normal strains is examined with the help of experiment and ANSYS analysis. In ANSYS, a simple modeling scheme is proposed for MFC using a parallel capacitors concept. The independent modal space control technique has been revisited to address the control of combination resonances through a selective modal space control scheme, where two or more modes can be combined to form the vibrating system or plant in modal domain. The developed control schemes are implemented in a digital processor using DS1104 and the closed-loop vibration control experiments are conducted on a CFRP shell structure. The influence of directionally induced actuation of MFC actuators on elastic couplings of composite shell is studied theoretically and is subsequently demonstrated in experiments. MFC actuators provide the much needed optimization domain for achieving the vibration control of combination resonances of elastically coupled deep-shell structure.
\end{abstract}

\section{Introduction}

Active control techniques are becoming more popular in recent years due to the emergence of a field called "Smart Materials and Structure." Smart materials such as piezoelectric, shape memory alloys, and magnetostrictive have got multi functional behaviors, namely, actuation, sensing, and load carrying. Among these, the electromechanically coupled piezoelectric materials possess immense potentials because of its dynamic characteristics (wider frequency band, large force) and their availability in different forms (bar, patch, composite, stack, etc.). Piezoelectric patches and composites such as Macrofibre Composite (MFC), Active Fibre Composite (AFC) are increasingly considered as actuators by research communities to address various vibration control-related problems in recent years [1-7].

Shell structures are commonly adopted in aerospace vehicles [8]. The wing panels, fuselage outer skins, tail panels, and so forth are constructed with shell structural elements using aluminum and composite materials. Light weight aerospace, naval and civil engineering structures usually employ shell configurations to attain structural efficiencies such as improved stiffness, desired shape, optimal weight, and aeroelastic characteristics. Although shell structures may provide these interesting features, they pose difficulties in terms of their complex geometries with a strong bendingmembrane and shear-membrane couplings, and so forth. Therefore, in order to build an efficient shell or a panel structure using composite materials (Carbon Fibre Reinforced Plastics, Glass Fibre Reinforced Plastics), advanced technologies such as active vibration control (AVC) may be beneficial. AVC techniques have been found useful to control the shell vibration modes $[9,10]$. Composite structures such as aircraft wing skin demand a variable thickness to avoid aeroelastic flutter of coupled modes; the panel vibration due to propeller tonal noise may result in more 


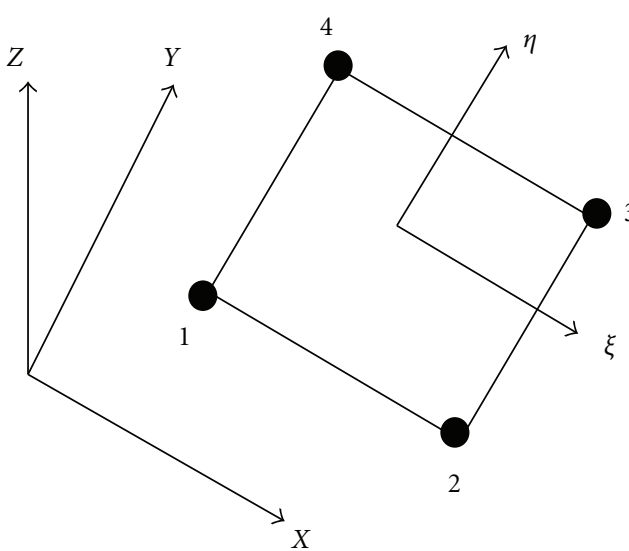

(a)

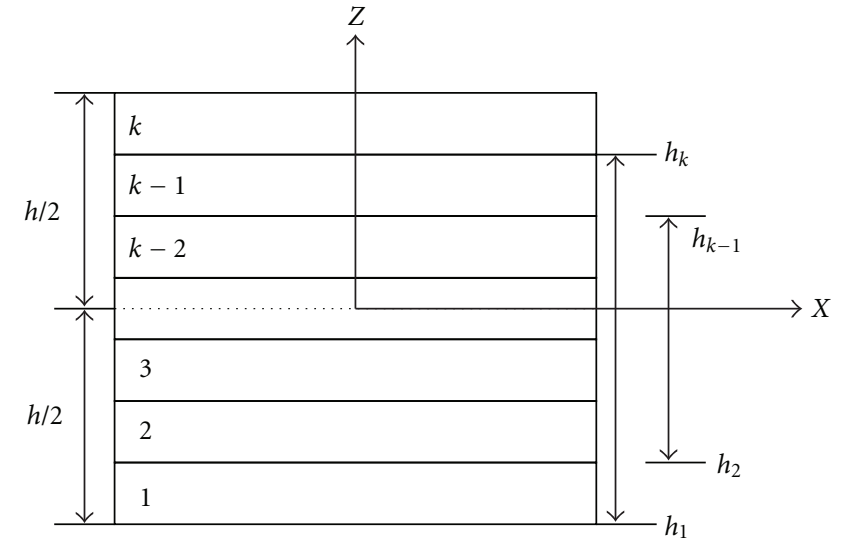

(b)

FIGURE 1: Electromechanically coupled composite facet element.

sound radiation into the cabin and become a greater design constraint for the transport aircrafts. Therefore, resonant and combination resonance control techniques in modal domain [11] would be beneficial to address above such vibration-related problems, where the resonant frequencies are expected to be excited either by structure borne/air-borne noises [12] or unsteady aerodynamics.

Vibration control of thin-shell structures involving modeling, analysis by piezoelectric materials has gained importance due to extension actuation, which couples the membrane strain effectively with an applied electric field [13-15]. Optimal placement of piezoelectric actuators on the curved surfaces has vastly improved their control performance on shell structures $[16,17]$. A simplified modeling technique was proposed for MFC actuators [18], which has encouraged the researchers to employ these very flexible actuating elements in real-time vibration control applications [19].

The review of relevant literatures has brought out the following observations.

(i) Use of MFC actuators for directional actuation has been found efficient.

(ii) Studies on isotropic beams, plates, and shells with piezoelectric patches are successfully conducted.

(iii) Beam, plate, and triangular shell finite elements are proposed with MFC actuators.

(iv) However, the study on composite shells with MFC actuators is very much limited; in particular the vibration control of a deep-shell configuration (like a fuselage panel) is not yet attempted.

(v) A simple and efficient electro mechanically coupled composite shell element, validated with experiment, may be required to analyze the curved composite skin/panel of aircraft structure with MFCs. The commercial codes such as ANSYS/ABAQUS have solid elements, which account for piezoelectric coupling; however aspect ratio of the solid element may be a constraint, dealing with the thin MFC's, when we employ them along with plate bending elements in a large structure.

(vi) Influence of in-plane actuation on the vibration control of coupled membrane-bending/membranetwisting of deep shell modes has to be evaluated to build an efficient AVC system to address resonant and combination resonances.

By keeping these objectives, a shear flexible, field consistent four-node facet-shell element has been proposed in the present work. Further a deep cylindrical shell $(\sim R / a=$ 1) made of CFRP is fabricated as an illustrative case and instrumented with three MFC actuators and three PZT patch sensors for conducting experimental studies. A full state feedback LQG controller is implemented in DS1104 DSP board to perform the resonant (single mode) and combination resonance (multiple modes) vibration control experiments. The independent modal space control (IMSC) and selective modal space control (SMSC) strategies are demonstrated to evaluate the performance of MFC actuators on a deep-shell vibration control application.

\section{Structural Modeling}

A four-node composite plate element, integrated with active layers has been formulated with five mechanical degrees of freedom $u_{0}, v_{0}, w_{0}, \theta_{x}, \theta_{y}$ and three electrical degrees of freedom $\varphi_{1 a}, \varphi_{2 a}, \varphi_{1 s}$ per node (see Figure 1). The linear displacement relations of this element are given by,

$$
\begin{gathered}
u(X, Y, Z, t)=u_{0}(X, Y, t)+z \theta_{y}(X, Y, t), \\
v(X, Y, Z, t)=v_{0}(X, Y, t)-z \theta_{x}(X, Y, t), \\
w(X, Y, Z, t)=w_{0}(X, Y, t),
\end{gathered}
$$

where, $u_{0}, v_{0}, w_{0}$ are the midplane deformations along $X, Y$, and $Z$ directions, respectively, and $\theta_{x}, \theta_{y}$ are the cross-section rotations in $Y Z$ and $X Z$ planes, respectively.

The formulation includes three piezoelectric layers, which can be placed anywhere along the thickness direction 
of the laminated composite shell. The total electric potential in each active layer is then given by

$$
\begin{aligned}
\varphi_{a 1}(X, Y, Z) & =\frac{\left(z-h_{k-1}\right)}{\left(h_{k}-h_{k-1}\right)} \varphi_{1 a}(X, Y), \\
\varphi_{a 2}(X, Y, Z) & =\frac{\left(z-h_{k-1}\right)}{\left(h_{k}-h_{k-1}\right)} \varphi_{2 a}(X, Y), \\
\varphi_{s}(X, Y, Z) & =\frac{\left(z-h_{k-1}\right)}{\left(h_{k}-h_{k-1}\right)} \varphi_{1 s}(X, Y),
\end{aligned}
$$

where $\varphi_{1 a}, \varphi_{2 a}, \varphi_{1 s}$ are the difference of potential between top and bottom surfaces of the active layer and subscripts " $a$ " and " $s$ " in the previous equations denote actuator and sensor, respectively.

In (2), $\varphi_{a 1}$ models $\mathrm{d}_{33}$ actuation and $\varphi_{a 2}$ accounts for $\mathrm{d}_{31}$ actuation. The material coordinate transformation is done for MFC actuation to accommodate the in-plane electric field in transverse direction [7]. Further the distance between two finger electrodes is considered to define the electric field to potential relation.

The kinematic relations are described for membrane, bending, and shear strain fields as follows:

$$
\begin{gathered}
\{\varepsilon\}=\left\{\varepsilon_{m b}, \gamma\right\}, \quad\left\{\varepsilon_{m b}\right\}=\left\{\varepsilon_{m}\right\}+z\left\{\varepsilon_{b}\right\}, \\
\left\{\varepsilon_{m}\right\}=\left\{\begin{array}{c}
\varepsilon_{x}^{m} \\
\varepsilon_{y}^{m} \\
\gamma_{x y}^{m}
\end{array}\right\}=\left\{\begin{array}{c}
\frac{\partial u_{0}}{\partial X} \\
\frac{\partial v_{0}}{\partial Y} \\
\frac{\partial u_{0}}{\partial Y}+\frac{\partial v_{0}}{\partial X}
\end{array}\right\}, \\
\left\{\varepsilon_{b}\right\}=\left\{\begin{array}{c}
\varepsilon_{x}^{b} \\
\varepsilon_{y}^{b} \\
\gamma_{x y}^{b}
\end{array}\right\}=\left\{\begin{array}{c}
\left(\frac{\partial \theta y}{\partial X}\right) \\
-\left(\frac{\partial \theta x}{\partial Y}\right) \\
\left(\frac{\partial \theta y}{\partial Y}-\frac{\partial \theta x}{\partial X}\right)
\end{array}\right\}, \\
\{\gamma\}=\left\{\begin{array}{c}
\gamma_{x z} \\
\gamma_{y z}
\end{array}\right\}=\left\{\begin{array}{c}
\left(\frac{\partial w}{\partial X}+\theta y\right) \\
\left(\frac{\partial w}{\partial Y}-\theta x\right)
\end{array}\right\} .
\end{gathered}
$$

Similarly the electric fields both in-plane and transverse direction are defined as

$$
\left\{E_{Z}\right\}_{i}=-\left\{\frac{\partial \varphi_{i}}{\partial Z}\right\}, \quad i=a 1, a 2, s .
$$

In (3a) and (3b), the superscripts $m, b$, denote membrane, bending, respectively; $\mathcal{\varepsilon}, \gamma$, and $E$ are normal strain, shear strain, and electric field, respectively.

The displacements and electric potentials are then approximated within the element using the linear shape functions [8], defined in generalized coordinates $(\xi, \eta)$ and as a result the final strain to displacement and electric field to potential relations are obtained in isoparametric co-ordinate system as follows:

$$
\begin{aligned}
& \{\varepsilon\}=\sum_{i=1,4}[J]^{-1}\left[B_{u}\right]_{i}\{\bar{u}\}_{i}, \\
& \{E\}=\sum_{i=1,4}[J]^{-1}\left[B_{\varphi}\right]_{i}\{\bar{\varphi}\}_{i},
\end{aligned}
$$

where $B_{u}(\xi, \eta)$ and $B_{\varphi}(\xi, \eta)$ are the spatial derivatives of shape functions of elastic and electric fields, respectively; they are obtained by introducing the shape functions into (3a) and ( $3 \mathrm{~b}) J$ is the Jacobian matrix, relating the two coordinate systems.

The final mechanical and electrical degrees of freedoms are presented below:

$$
\begin{gathered}
\{\bar{u}\}=\left\{u_{0}, v_{0}, w, \theta_{x}, \theta_{y}\right\}^{T} \\
\{\bar{\varphi}\}=\left\{\varphi_{1 a}, \varphi_{2 a}, \varphi_{1 s}\right\}^{T} .
\end{gathered}
$$

The work done in the piezoelectric continuum acting as an actuator and a sensor is expressed, following the virtual work principle as

$$
\begin{gathered}
\delta U_{a}=\int_{v}\left(\rho \ddot{u}_{j} \delta u_{j}+\sigma_{i j} \delta \varepsilon_{i j}\right) d v-\int_{s}\left(f_{s j} \delta u_{j}\right) d s, \\
\delta U_{s}=\int_{v}\left(D_{i} \delta \varphi_{, i}\right) d v-\int_{s}(q \delta \varphi) d s,
\end{gathered}
$$

where $u, \sigma, f_{s}, D$, and $q$ are the displacement, density, stress, surface traction, electric displacement, and charge, respectively.

Using the kinematics (4a) and (4b) the constitutive material properties [7], the coupled energy equation (5) may be numerically approximated and derived in terms of nodal displacements and nodal voltages as follows:

$$
\left[M_{u u}\right]\{\ddot{\bar{u}}\}+\left[K_{u u}\right]\{\bar{u}\}+\left[K_{u \varphi}\right]\{\bar{\varphi}\}=\left\{F_{m}\right\},
$$

where $M_{u u}$ is the mass matrix, $K_{u u}$ is the stiffness matrix, $K_{u \varphi}$ is the actuator matrix, and $F_{m}$ is the mechanical load vector.

Similarly the sensor equation is given by

$$
\left[K_{\varphi u}\right]\{\bar{u}\}+\left[K_{\varphi \varphi}\right]\{\bar{\varphi}\}=0,
$$

where $K_{\varphi u}$ is the sensor matrix and $K_{\varphi \varphi}$ is the electric capacitance matrix.

2.1. Facet-Shell Element and Warping Correction. The force and moment corrections are done on this four-node element, following Naganarayana and Prathap [20] to incorporate warping improvement in the element. For the sake of clarity, the procedure is briefly explained here. The composite plate element is made as a facet-shell element, allowing it to have a non-co-planarity of the four nodes (i.e., inplane and out-of-plane transformation). Let the local and global Cartesian coordinates be represented by $x, y, z$ and $X, Y, Z$, respectively. The element matrices thus obtained in isoparametric co-ordinates $(\xi, \eta)$ are transformed into local system of coordinates and then finally assembled in global system. This transformation is required in order to model the conformable MFC over the curved shell surface.

Six global mechanical degrees of freedom are considered, that is, $\left\{\begin{array}{lllllll}U & V & W & \theta_{X} & \theta_{Y} & \theta_{Z}\end{array}\right\}^{T}$; however the plate element has only five $\left\{\begin{array}{llllll}u_{0} & v_{0} & w_{0} & \theta_{x} & \theta_{y} & \theta_{z}\end{array}\right\}^{T}$. Inclusion of the third rotation and its associated stiffness has got obvious benefits to improve the facet element for predicting the out-ofplane piezoelectric shell behavior. In fact the dynamics of 
shell structure is dominated both by membrane and outof-plane deformations; therefore to accurately model the induced deflection of MFC on the shell, warping correction is included.

If the set of assembled equilibrium equations in local coordinates is considered at each nodal point, then we have six equations of which the last one (corresponding to $\theta_{z}$ direction) is simply $m \ddot{\theta}_{z}+k \theta_{z}=0$, where $m$ is the rotary inertia and $k$ is the assumed stiffness at the element level. The matrix for transforming the local coordinates to global coordinates is obtained as

$$
\{U\}=[T]\{u\}
$$

where

$$
\begin{gathered}
{[T]=\left[\begin{array}{ccc}
{[\alpha]} & 0 & 0 \\
0 & {[\alpha]} & 0 \\
0 & 0 & I
\end{array}\right] ;} \\
\left\langle\begin{array}{c}
\left.\{U\}=\left\{\begin{array}{lllllllll}
U & V & W & \theta_{X} & \theta_{Y} & \theta_{Z} & \phi_{1 A i} & \phi_{2 A i} & \phi_{1 S i}
\end{array}\right\}^{T}\right\rangle \\
\{u\}=\left\{\begin{array}{lllllllll}
u_{0} & v_{0} & w & \theta_{x} & \theta_{y} & \theta_{z} & \varphi_{1 a i} & \varphi_{2 a i} & \varphi_{1 s i}
\end{array}\right\}^{T}
\end{array}\right.
\end{gathered}
$$

$\left(\phi_{1 A i}\left(\varphi_{1 a i}\right), \phi_{2 A i}\left(\varphi_{2 a i}\right), \phi_{1 S i}\left(\varphi_{1 s i}\right)\right.$ represent the electrical degrees of freedom of the facet-shell element in global (local) coordinates and $\alpha$ is the direction cosine of local coordinates. The global element stiffness, mass matrix, and force vector are thus obtained in their final form using the local element matrices as

$$
\begin{gathered}
{\left[K^{g}\right]=[T]^{T}\left[K^{l}\right][T],} \\
{\left[M^{g}\right]=[T]^{T}\left[M^{l}\right][T],} \\
\left\{F^{g}\right\}=[T]^{T}\left\{F^{l}\right\},
\end{gathered}
$$

where superscripts " $g$ ", "l" denote global and local coordinate system, respectively.

2.2. Shear Locking Correction. The membrane in-plane shear locking $\left(\gamma_{x y}^{m}\right)$ has been corrected in the present element using one-point Gaussian quadrature along $\xi$ and $\eta$ directions; bending shear locking $\left(\gamma_{x y}^{b}\right)$ is performed by the expression: $\gamma_{x y}^{b}=2 \gamma_{x y}^{2 \times 2}-\gamma_{x y}^{1 \times 1}$, where $2 \times 2$ implies that the element has been evaluated at four Gaussian points in the element and $1 \times 1$ means the evaluation point at the centre of the element. Further, out-of-plane shear corrections have been incorporated through $1 \times 2$ and $2 \times 1$ integration points for $\gamma_{x z}$ and $\gamma_{y z}$ shear terms, respectively.

\section{Control Modeling}

In this section, the control procedure is briefly explained. A linear quadratic regulator is designed in modal domain using the system matrices, obtained from finite element analysis. The stiffness, mass, actuator, and sensor matrices of the shell are obtained in uncoupled form in modal domain by transforming them from physical coordinates $(X, Y, Z)$ using modal orthogonality relations (mode shape vectors).

The dynamic equation is then written in modal form as

$$
\begin{aligned}
\bar{M}_{u u} \ddot{\zeta}+\bar{D}_{u u} \dot{\zeta} & +\bar{K}_{u u} \zeta-\bar{K}_{u \phi}=\bar{F}_{d}, \\
\bar{M}_{u u} & =\psi^{T} M_{u u} \psi, \\
\bar{D}_{u u} & =\psi^{T} D_{u u} \psi, \\
\bar{K}_{u u} & =\psi^{T} K_{u u} \psi, \\
\bar{K}_{u \phi} & =\psi^{T} K_{u \phi}, \\
\bar{F}_{d} & =\psi^{T} F_{m},
\end{aligned}
$$

where $\psi$ is the modal vector.

Further, the closed-loop system is built using the dynamic equation in state space form as follows:

$$
\begin{gathered}
\dot{\chi}(t)=A \chi(t)+B \phi_{a}(t)+\beta(t), \\
\phi_{s}(t)=C \chi+\nu(t) .
\end{gathered}
$$

Equation (12) can be defined for ith mode using the independent modal space control (IMSC) approach in statespace format as follows:

$$
\begin{aligned}
& A_{i}=\left[\begin{array}{cc}
-2 \zeta_{i} \omega_{i} & \omega_{i} \\
-\omega_{i} & 0
\end{array}\right], \quad B_{i}=\left[\begin{array}{cc}
\bar{F}_{d}(i) & \bar{K}_{u \phi}(i, a) \\
0 & 0
\end{array}\right],
\end{aligned}
$$

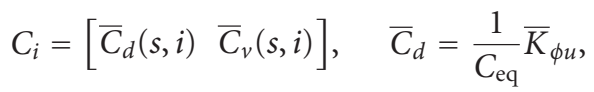

$$
\begin{aligned}
& \bar{C}_{v}=R_{\mathrm{eq}} \bar{K}_{\phi u}, \bar{K}_{\phi u}=K_{\phi u} \psi,
\end{aligned}
$$

where $R_{\mathrm{eq}}$ is the equivalent circuit resistance and $C_{\mathrm{eq}}$ is the equivalent circuit capacitance, " $s$ " is the number of sensors (3 no's), " $a$ " is the number of actuators ( 3 no's), $\omega$ is the frequency of vibration, and $\zeta$ is the modal damping.

The control design has taken into account the process disturbance $(\beta)$ and the measurement noise $(\nu)$.

Therefore the final closed-loop system is built with a liner control law as

$$
\begin{gathered}
\dot{\chi}=\left(A-B G_{c}-G_{e} C\right) \chi+G_{e} \phi_{s}, \\
\phi_{a}=-G_{c} \chi .
\end{gathered}
$$

Both LQR gain $\left(G_{c}\right)$ and Kalman filter gain $\left(G_{e}\right)$ are computed by minimizing the quadratic performance index, involving shell matrices and associated weighting vectors of $Q_{c}, R_{c}, Q_{e}, R_{e}$, respectively. The subscripts $c$ and $e$ denote controller and estimator, respectively. Though IMSC appears to be efficient for single-mode control, two such modal models cannot be simply added to build a control model for conducting combination resonance control. The issues such as out of bandwidth correction and control spill over must be addressed. For practical application such as vibroacoustic control of fuselage panels, subjected to tonal noise (harmonics) or flutter of lifting surfaces (bendingtorsion), control of more than one resonant frequencies need to be considered. Therefore, a selective modal space control approach (SMSC) is proposed, in which the feasible modal models are combined with common actuators' and sensors' configuration. SMSC will help to pick up the critical modes at the design stage itself and provide the necessary information such as optimal number of actuators and their locations because the plant matrices contain those details. 
TABLE 1: Deflection in $\mu \mathrm{m}$.

\begin{tabular}{lcccc}
\hline Radius $(\mathrm{cm})$ & 20 & 30 & 40 & 50 \\
\hline Reference [14] & 3.42 & 4.22 & 4.73 & 4.91 \\
Present FEM & 3.41 & 4.25 & 4.67 & 4.95 \\
\hline
\end{tabular}

\section{Numerical Studies}

The developed shell4 element has been validated first for its capability to solve static, dynamic, and piezoelectric problems. For this purpose, we have adopted both numerical and experimental approaches.

4.1. Validation Studies. A clamped circular cylinder with an applied potential on the whole upper $(V=100)$ and lower $(V=0)$ surfaces is considered to validate the proposed facetshell element. The geometry and electrical potentials are taken, following [14]. The obtained deflections are presented in Table 1.

In order to validate the dynamic behavior of the developed element, a simply supported laminated cylindrical shell is considered with $a / h=100$ and $a / b=1$. The geometry and material properties are taken from Reddy [8]. The obtained free vibration frequencies of the laminated cylindrical shells (different $R / a$ configurations) are presented in Table 2. It can be seen that the present shell 4 has predicted very closely the natural frequencies with those reported in the reference. Therefore, it is understood that the shell4 can be employed to solve electro-mechanically coupled composite shell structures with piezoelectric actuators and sensors.

4.2. Electromechanical Coupling and Free Vibration Analysis. For an illustration of combination resonance control, a deep cylindrical shell is considered (see Figure 2). The cylindrical composite shell is made of CFRP and its dimensions, material properties are presented in Table 3 . Finite element analysis is performed using the proposed shell4 element in MATLAB and as well as in ANSYS. In ANSYS, "Solid 5 " element is employed to idealize the MFC actuators and PZT sensor patches. A simple modeling scheme is developed to compute the induced in-plane actuation $\left(\mathrm{d}_{33}\right)$ of MFC, by adopting an equivalent electric field ideology (refer to Figure 3). In this approach, the behavior of MFC is modeled similar to parallel capacitors.

The finger electrode width and the required electric field are simulated by assuming a suitable element width and its associated element potential to be imposed as boundary conditions.

The actual electrode area is $L_{a} \times b$ and equivalent finger electrode width is taken as $L_{f}$. The number of elements is chosen such that the actual active area of the MFC is enveloped. A linear electric field is assumed with $E_{\text {simulated }}=$ equivalent potential/equivalent finger electrode width. Thus $E_{\text {estimated }}$ is made equivalent to $E_{\text {required, }}$, where $E_{\text {required }}$ is the actual potential/actual finger electrode width.

Before generating the system matrices for controller design, the modeling scheme of MFC in finite element procedure is validated with experiment and ANSYS analysis.

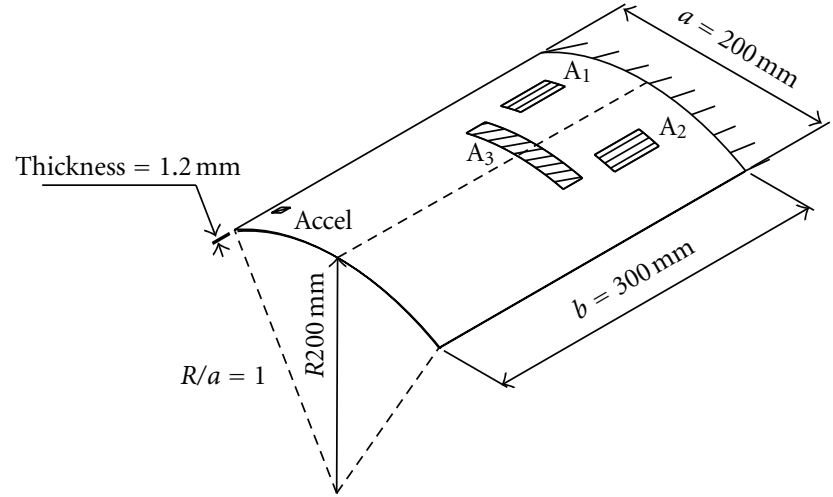

Figure 2: Cylindrical composite shell.

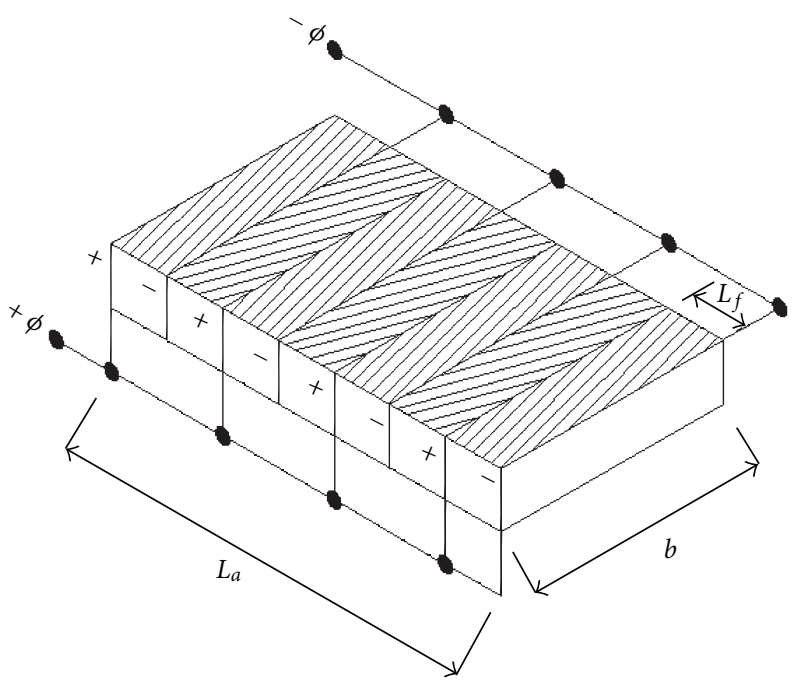

FIGURE 3: MFC actuator modeling scheme in ANSYS.

For this purpose we have used only two actuators $A_{1}$ and $A_{2}$ on the shell structure, which means that the third actuator is not bonded at this stage during experimental study. Table 4 presents the deflections measured and numerically computed for three different cases, namely, (i) $A_{1}$ and $A_{2}$ active, (ii) $A_{1}$ active, and (iii) $A_{2}$ active. It can be seen that a quite good comparison is observed between theory and experiment for the applied 1000 volts. Therefore the closedloop control experiments are planned within \pm 500 volts.

The free vibration analysis is carried out to compute the frequencies and mode shapes. The results are presented in Table 5 and in Figure 4. It is noticed that the shell first mode is a pure torsion but second, third, and fourth modes are coupled bending-torsion type.

The experimentally measured frequencies are listed in Table 5 along with the associated damping values. The modes are properly identified and a good correlation is noticed.

The simulation studies are performed under sine disturbances, before implementing the designed controller in hardware-in-loop experiments. Resonance mode control (IMSC), combination resonance control (SMSC) concepts have been attempted on the composite shell structure. 
TABLe 2: Nondimensional fundamental frequencies of cylindrical shell under uniformly distributed load.

\begin{tabular}{lccc}
\hline$R / a$ & Reddy $[8]$ & Present $a / h=100, a / b=1.0,\left[0^{\circ} / 90^{\circ} / 90^{\circ} / 0^{\circ}\right]$ & 28.948 \\
& & $8 \times 8$ mesh & $16 \times 16$ mesh \\
\hline 5 & 28.825 & 29.335 & 16.765 \\
10 & 16.706 & 11.945 & 11.868 \\
20 & 11.841 & 10.118 & 10.076 \\
50 & 10.063 & 9.829 & 9.794 \\
100 & 9.782 & 9.730 & 9.697 \\
$10^{30}$ & 9.687 & & \\
\hline
\end{tabular}

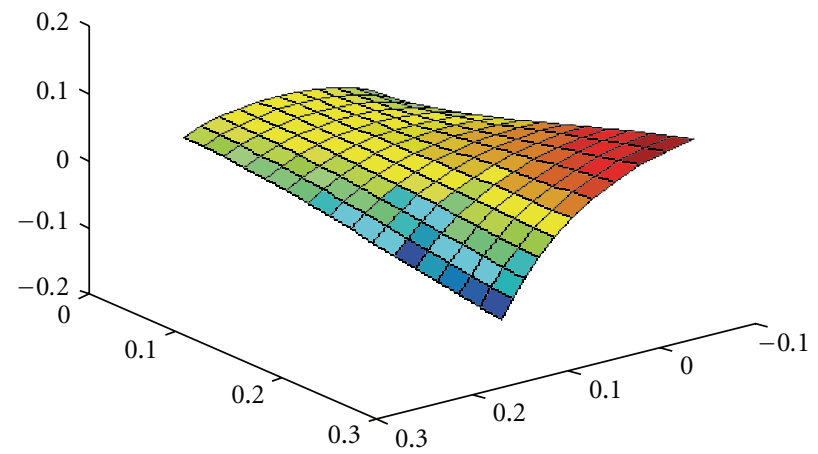

(a)

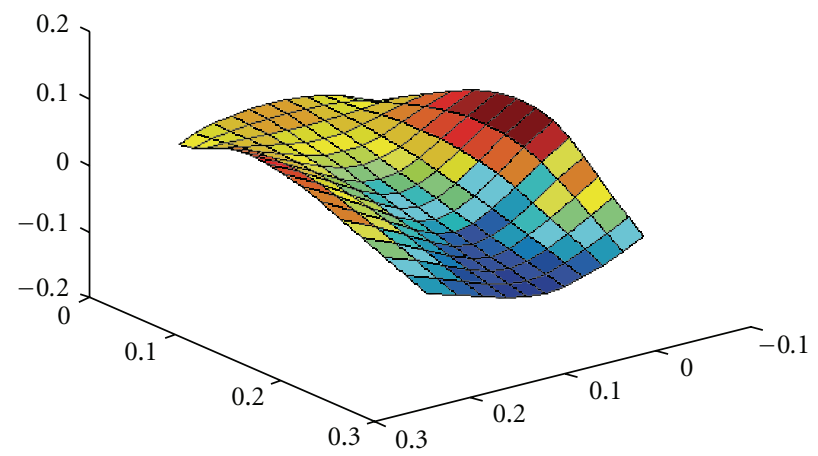

(c)

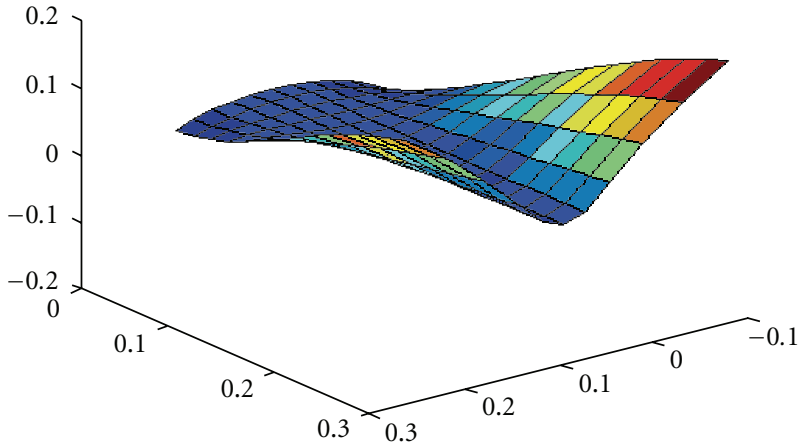

(b)

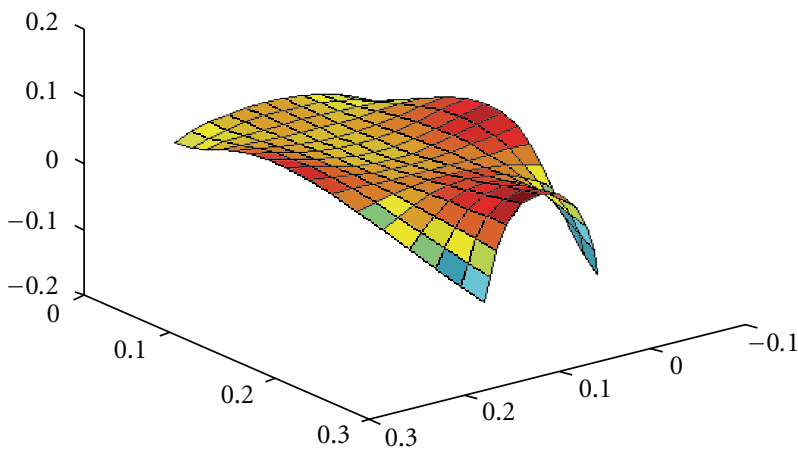

(d)

FIGURE 4: Shell mode shapes.

The computed control gains are presented in terms of actuator voltages in Table 6 for both cases. It can be seen that the designed controller has effectively suppressed the first four modes of the composite shell independently. The combination resonance also has shown promising results, which makes MFCs to target multiple modes simultaneously. Figures 5 and 6 show few simulation results of both IMSC and SMSC control scheme, respectively.

\section{Experimental Scheme}

Development of active vibration control scheme consists of controller design and its implementation with analog or digital instrumentation. In most of the industrial applications, PID control finds a major place for its simplicity; however tuning a PID controller for particular environment may not work or be feasible for every loading conditions. Therefore, modern control concepts are considered to address the system performance in a wider spectrum of loadings, including the system uncertainties. Linear Quadratic Regulator (LQR) is a simple and effective control algorithm; but in order to implement this algorithm for real-time application, there is a need to have the full state information of the vibrating system. A full state feedback based on LQR is practically feasible with Kalman filter as a system estimator. Therefore, in the present work, we have adopted modal Kalman filter along with the modal LQR controller in order to implement both independent (IMSC) and selective modal control (SMSC) schemes. System information is read in the form of displacement through PZT patches, surface bonded below the composite shell, and velocity information is subsequently estimated through Kalman filter. 
TABLE 3: Material properties of CFRP, MFC, PZT-5A.

\begin{tabular}{|c|c|c|c|}
\hline Material Property & CFRP (BDC) & MFC & PZT-5A \\
\hline Young's modulus $E_{11}$ & $34.29 \mathrm{GPa}$ & $30.25 \mathrm{GPa}$ & $48 \mathrm{GPa}$ \\
\hline Young's modulus $E_{22}$ & $34.29 \mathrm{GPa}$ & $15.99 \mathrm{GPa}$ & $48 \mathrm{GPa}$ \\
\hline Shear modulus $G_{12}$ & $2.0 \mathrm{GPa}$ & $5.5 \mathrm{GPa}$ & $18.32 \mathrm{GPa}$ \\
\hline Poisson's ratio $v_{12}$ & 0.2 & 0.306 & 0.31 \\
\hline Poisson's ratio $\nu_{13}$ & 0.2 & 0.306 & 0.31 \\
\hline Density $\rho$ & $1333 \mathrm{Kg} / \mathrm{m}^{3}$ & $5020 \mathrm{Kg} / \mathrm{m}^{3}$ & $7500 \mathrm{Kg} / \mathrm{m}^{3}$ \\
\hline $\begin{array}{l}\text { Piezoelectric Stress } \\
\text { constant }\left(e_{11}\right)\end{array}$ & - & $13.954 \mathrm{C} / \mathrm{m}^{2}$ & - \\
\hline $\begin{array}{l}\text { Piezoelectric Stress } \\
\text { constant }\left(e_{12}\right)\end{array}$ & - & $-5.868 \mathrm{C} / \mathrm{m}^{2}$ & $13.152 \mathrm{C} / \mathrm{m}^{2}$ \\
\hline Dielectric constant & - & $\begin{array}{c}1.42 \times \\
10^{-8} \mathrm{~F} / \mathrm{m}\end{array}$ & $\begin{array}{c}3.01 \times \\
10^{-8} \mathrm{~F} / \mathrm{m}\end{array}$ \\
\hline
\end{tabular}

Geometric of CFRP cylindrical shell. Length $(b)=300 \mathrm{~mm}$; width $(a)=$ $200 \mathrm{~mm}$; radius $(R)=200 \mathrm{~mm}$; thickness $(t)=1.2 \mathrm{~mm}$ and $R / a=1$.

5.1. AVC Instrumentation. The composite cylindrical shell is fabricated using CFRP bidirectional cloth, subsequently instrumented with three MFC actuators on the top. The following actuators of Smart Materials are used: M4010 P1, active area $40 \times 10 \mathrm{~mm}^{2}$ and M8528 F1, active area $85 \times$ $28 \mathrm{~mm}^{2}$. In order to have a collocated actuator and sensor configuration, three PZT-5A patches are surface bonded, right below every MFC actuator. The location for the actuators are chosen based on the mode shape such that the actuators $A_{1}$ and $A_{2}$ will target the first and second modes Actuator $A_{3}$ will be used for the third and fourth modes control. Figure 7 displays the AVC instrumentation, employed in the closed-loop experiments. The instrumentation consists of following:

(i) Instrumentation for applying the disturbance,

(ii) Sensor electronics,

(iii) Actuator electronics,

(iv) DSP.

Three PZT patches are employed as feedback sensors; in addition, an accelerometer is used at the tip of the shell for observation purpose. A charge conditioner is used for collecting the output of accelerometer and force transducer. The disturbance loop consists of a signal generator, power amplifier, and a force transducer. The charges induced from the PZT patches are received by sensor electronics and are fed into the ADCs of DS 1104 board. The LQG controller is implemented with the help of real-time workshop/RTI software as SIMULINK block set; refer to Figure 8 for details. The high impedance sensor signals are collected through charge to voltage conversion circuits and conditioned with suitable sensor gains.

A virtual instrumentation panel is created in control desk (dSPACE product) to monitor the disturbance force, sensors' output, and actuators' input. It facilitates to fine-tune the control gains of the actuators in real time (see Table 6).

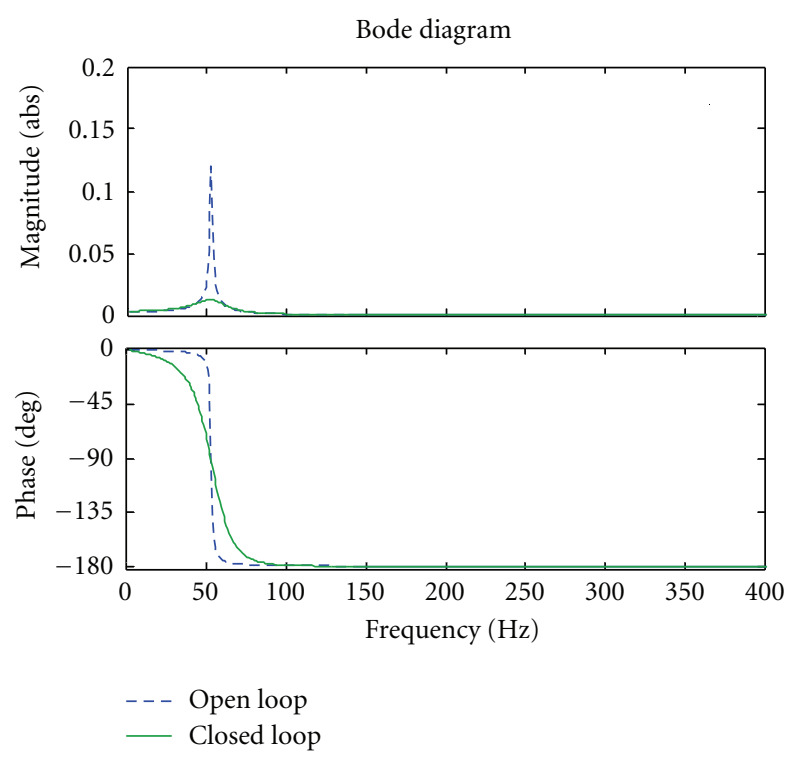

(a) Bode response of the first mode $(52.12 \mathrm{~Hz})$

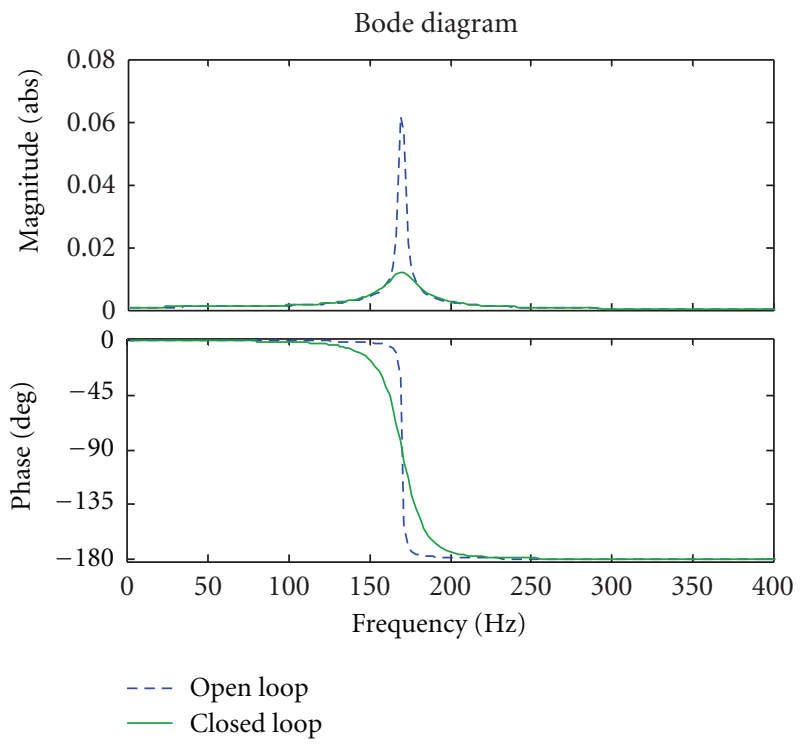

(b) Bode response of the third mode $(171.43 \mathrm{~Hz})$

FIGURE 5: Frequency response plots of LQG (IMSC) scheme.

Indeed the on/off control will be more efficient once we schedule the control gains for different disturbances. The processed signals (control inputs) are then taken through the DACs of DS1104 and supplied to the high-voltage amplifiers of Smart Materials. These amplifiers have got an inbuilt gain of 200; therefore while tuning the designed LQG gain, this value has been taken into account. MFC actuators can be used with -500 to $1500 \mathrm{VDC}$ in quasi-static applications; however in dynamic case they can be used in the range of \pm 500 VAC without DC biasing or \pm 750 VAC with DC biasing. In the present application, we have used MFCs within \pm 500 VAC without DC biasing. Care is taken for proper insulation, isolation of the actuators, and wiring is done so as to avoid any electric leakage. 
TABLE 4: Induced deflection of shell with two MFC actuators.

\begin{tabular}{lcccccc}
\hline \multirow{2}{*}{ Actuator state } & \multicolumn{2}{c}{ Experiment } & \multicolumn{2}{c}{ Shell facet element } & \multicolumn{2}{c}{ ANSYS } \\
& Position A & Position B & Position A & Position B & Position A & Position B \\
& Disp $(\mathrm{mm})$ & Disp $(\mathrm{mm})$ & Disp $(\mathrm{mm})$ & Disp $(\mathrm{mm})$ & Disp (mm) & Disp (mm) \\
\hline$A_{1}$ and $A_{2}$ active & 0.025 & 0.028 & 0.027 & 0.027 & 0.026 & 0.026 \\
$A_{1}$ active & - & 0.085 & -0.052 & 0.079 & -0.053 & 0.077 \\
$A_{2}$ active & 0.085 & - & 0.079 & -0.052 & 0.077 & -0.053 \\
\hline
\end{tabular}

Position A $(X=300 \mathrm{~mm}, Y=0, Z=0)$. Position B $(X=300 \mathrm{~mm}, Y=200 \mathrm{~mm}, Z=0)$.

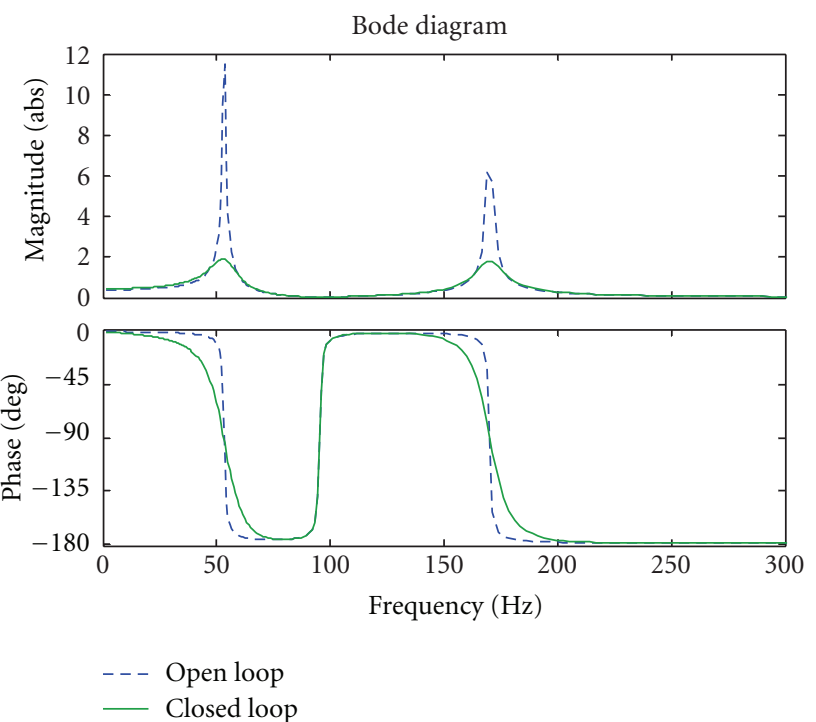

FIGURE 6: Bode response of selective modes 1 and 3 using LQG (SMSC) scheme.

TABLE 5: Dynamics of composite shell.

\begin{tabular}{lccc}
\hline Mode number & \multicolumn{2}{c}{ Frequency $(\mathrm{Hz})$} & Damping \\
& Experiment & $\begin{array}{c}\text { FEM } \\
\text { (Present) }\end{array}$ & \\
\hline Shell mode 1 & 53.4 & 52.12 & 1.24 \\
Shell mode 2 & 95.3 & 103.46 & 0.77 \\
Shell mode 3 & 170.2 & 171.43 & 0.38 \\
Shell mode 4 & 186.1 & 193.05 & 0.36 \\
\hline
\end{tabular}

TABLE 6: Voltages applied to actuators for control of various modes.

\begin{tabular}{lccc}
\hline Mode(s) & \multicolumn{3}{c}{ Actuator voltage in (volts) } \\
& $A_{1}$ & $A_{2}$ & $A_{3}$ \\
\hline 1 & 44 & 44 & - \\
2 & 96 & 88 & - \\
3 & - & - & 48 \\
4 & - & - & 96 \\
1 and 3 & 35 & 35 & 60 \\
2 and 4 & 60 & 60 & 60 \\
\hline
\end{tabular}

5.2. Open-Loop and Closed-Loop Experiments. A thorough modal survey is performed on the shell to establish its frequencies, damping for the first four modes (see Table 5). Active vibration control experiments are then conducted using independent modal controller, that is, IMSC as well as selective modal control (SMSC) approaches. A typical modal controller (Simulink model) that has been implemented is shown in Figure 8.

The Linear Quadratic Gaussian (LQG) controller has been designed such that each mode is significantly controlled through independent modal space control (IMSC) scheme. The effectiveness of modal control concept for multiple modes is examined through a combination resonance or selective modal space control (SMSC) technique. For this purpose, two modal sets are selected, namely, 1, 3 and 2, 4. The state-space matrices of selective modes are combined to form a single system with multiple target modes. Furthermore, LQG control is designed for these combination resonances. Modal coupling is a normal phenomenon in thin-walled composite shell structures; with the presence of aerodynamics, noise, and so forth, the coupled problems such as aeroelasticity, vibroacoustics may pose serious challenges for the designers. Therefore, in such situations, the selective modal control may certainly improve the structural performances and reduce the control spillover and number of actuators.

In order to examine the usefulness of the developed SMSC technique, we have conducted active control experiments on the cylindrical CFRP shell. The AVC experiments are conducted by implementing the designed LQG (IMSC) and LQG (SMSC) controllers in DS1104, an R \& D DSP board of dSPACE. The DSP has got multichannel ADCs and DACs, which are used for setting the multi-channel closedloop configuration. The actuators $A_{1}$ and $A_{2}$ are made to work for the first and second modes' control; on the other hand, the chordwise placed actuator $A_{3}$ has targeted the third and fourth modes. The outcome of the experiments is presented as power spectral densities in Figures 9 and 10. Table 7 shows the comparison of both IMSC and SMSC techniques in controlling the various modes. Accelerometer (sensitivity $100 \mathrm{mV} / \mathrm{g}$ ) is employed as the observation sensor, which is located at the tip of the shell; the disturbance force is monitored through a force transducer.

\section{Results and Discussions}

The experimental structure considered is actually a deepshell category, and therefore its elastic couplings appear to be very significant. Hence the first four modes are targeted to demonstrate the ability of in-plane actuation of MFC's 


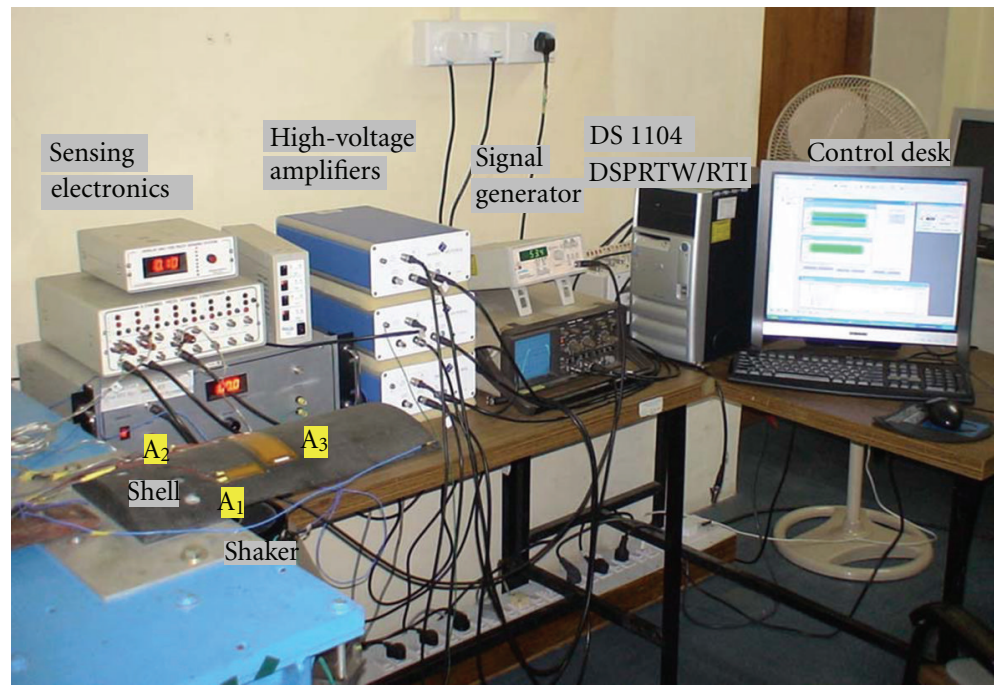

Figure 7: Experimental setup.

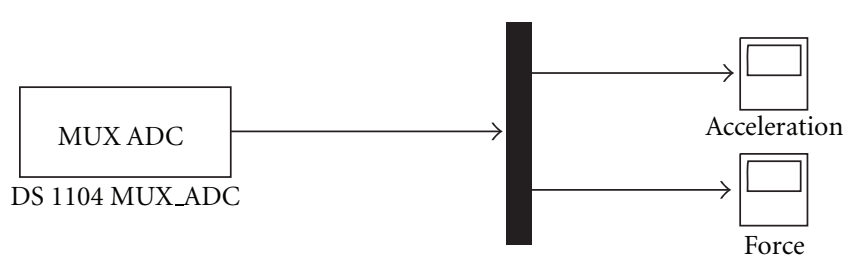

(a)

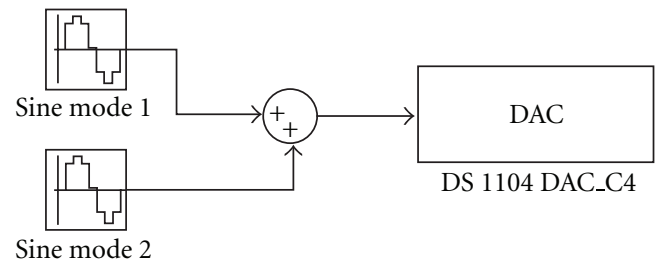

(b)

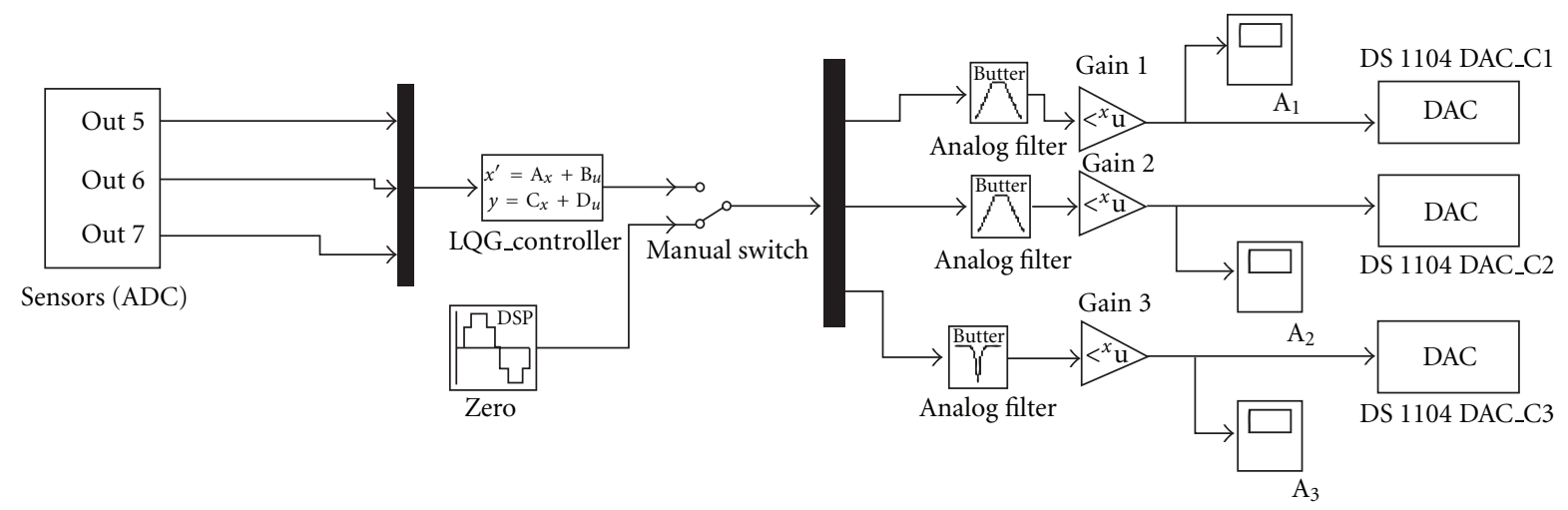

(c)

FIGURE 8: Simulink model of LQG controller.

in controlling the out-of-plane elastic couplings. The PZT fibers are oriented in actuators $A_{1}$ and $A_{2}$ along the length (spanwise) of the shell; thus they are expected to induce actuation strains to counteract first two shell modes, which are predominantly spanwise dominated. However, they are found less effective to control the third and fourth modes, which are chord wise dominated. Accordingly, the third actuator $\left(A_{3}\right)$ has been located, in which the PZT fibers are oriented at 45 degree. A mechanical disturbance is applied on the cylindrical shell and the response is subsequently measured through an accelerometer. The results are presented in Figures 9 and 10 and in Table 7.
The outcome of the experiments is examined and the following observations are made.

(i) Directionally efficient MFC actuators can be effectively employed in IMSC scheme of composite shell or panel vibrations for example, cases like a tonalnoise induced vibro-acoustic response control (refer Figures 9(a) and 9(b), where mostly the fundamental harmonics are to be suppressed.

(ii) In-plane actuation strain of MFC can be effectively tailored with elastic couplings of shell structures, namely, membrane-bending, membrane-shear, and 


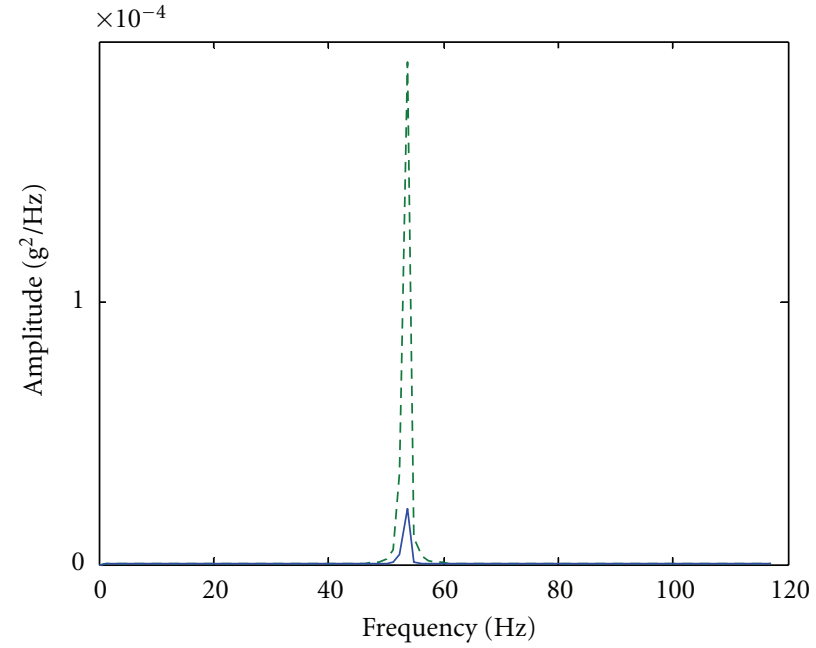

(a) Shell Mode 1

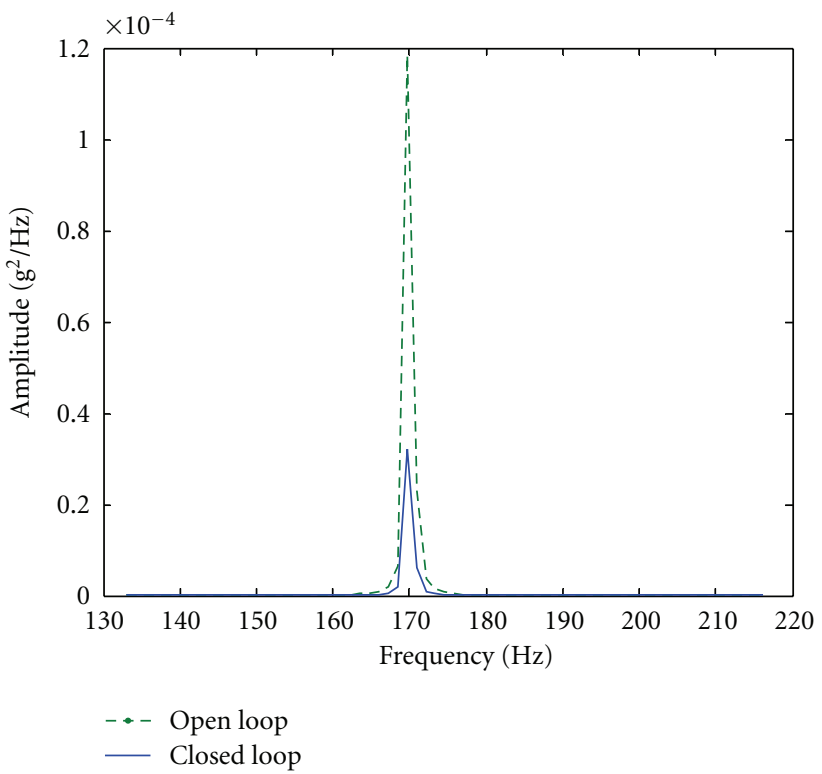

(c) Shell mode 3

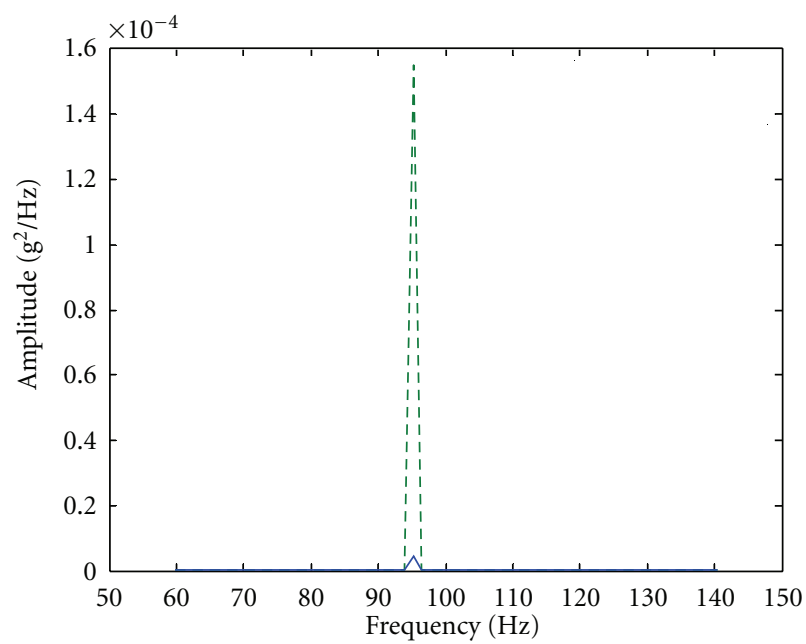

(b) Shell mode 2

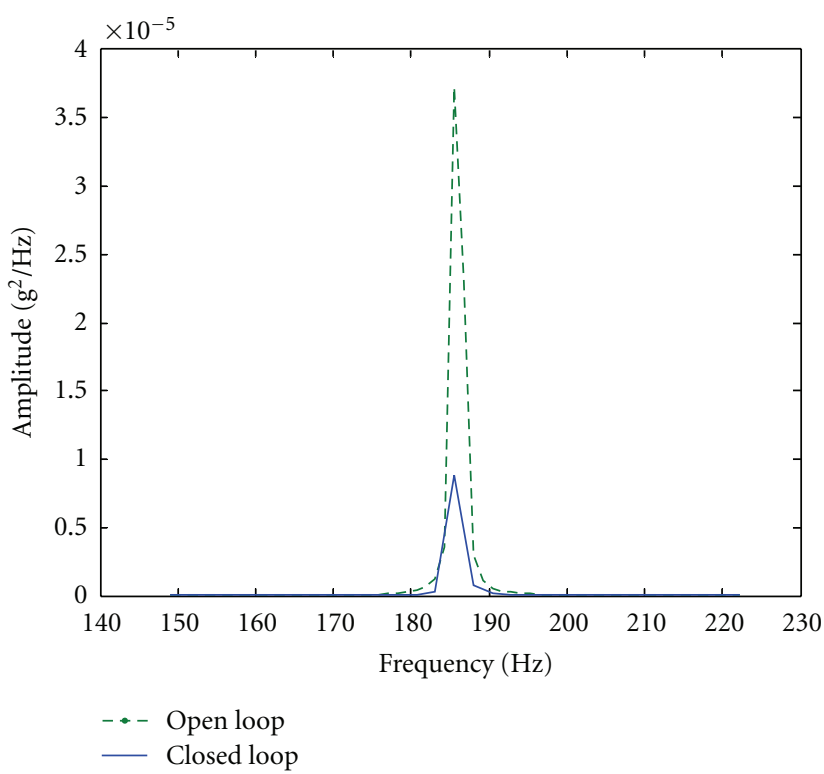

(d) Shell mode 4

FIGURE 9: Resonant mode control (IMSC).

TABLE 7: Comparison of control performances by IMSC and SMSC schemes.

\begin{tabular}{lccc}
\hline Mode(s) & $\begin{array}{c}\text { Open-loop } \\
\text { response in g } \\
\left(\mathrm{m} / \mathrm{sec}^{2}\right)\end{array}$ & $\begin{array}{c}\text { Closed-loop } \\
\text { response in g } \\
\left(\mathrm{m} / \mathrm{sec}^{2}\right)\end{array}$ & \% Control \\
\hline 1 & 3.6 & 1.0 & 83.15 \\
2 & 2.8 & 0.4 & 96.86 \\
3 & 2.9 & 1.2 & 73.33 \\
4 & 2.0 & 1.0 & 72.97 \\
1 and 3 & 4.6 & 2.3 & 66 and 82 \\
2 and 4 & 4.6 & 2.4 & 85 and 69 \\
\hline
\end{tabular}

membrane-twisting. It is shown by the actuator performance of $A_{3}$ on third and fourth modes' control (refer to Figures 9(c) and 9(d)), in which 45-degree oriented PZT fibers effectively control the coupled bending-torsion vibration.

(iii) SMSC technique is observed to be very useful for combination resonances especially for the $2 \mathrm{nd}$ and 4 th modes, where one can notice that independently the actuators $A_{1}(96 \mathrm{v}), A_{2}(88 \mathrm{v}), A_{3}(96 \mathrm{v})$ have performed to achieve $83.15 \%$ control in 2 nd mode and $72.97 \%$ control in 4th mode; however in combination. resonance control all the three actuators are operated only at $60 \mathrm{v}$ and around $77 \%$ control is achieved.

(iv) In the 1st and 3rd modes' control, though the trend appears to be same, only marginal benefit is seen from power saving point of view; however 


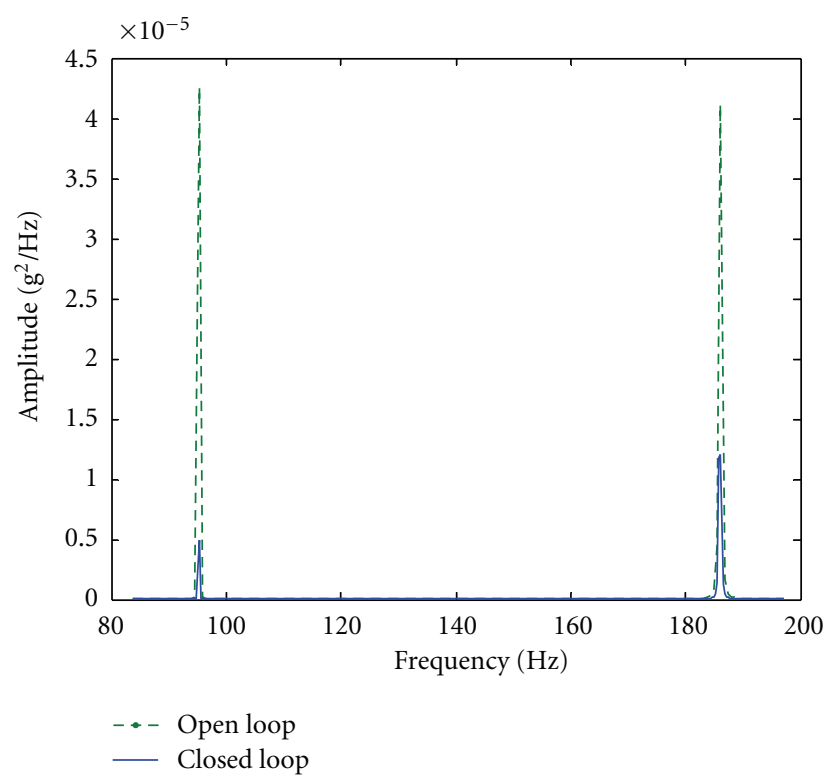

(a) Selective shell modes control (1 and 3)

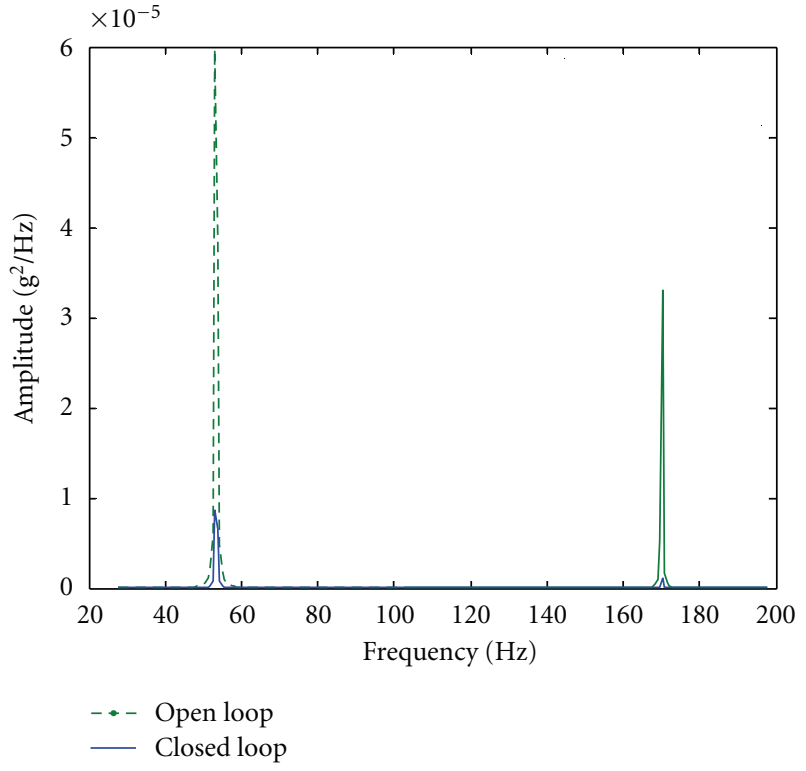

(b) Selective shell modes control (2 and 4)

FIgURE 10: Selective modal space control technique (SMSC).

from control spill over consideration, combination resonance shows a promising feature because both modes are simultaneously controlled.

(v) The developed facet-shell element is efficient in modeling composite shell with MFC and is incorporated in ANSYS for large smart structural analysis.

The user programmable feature (UPF) available in ANSYS is utilized (USER300 subroutine) to implement the shell4 piezoelectric composite element. We have employed the developed coupled FE procedure with our own degrees of freedoms (mechanical and electrical) to compute the element matrices (stiffness, mass, and piezoelectric). The MATLAB codes are rewritten in Visual Intel FORTRAN for this purpose. The other features (preprocessor, solver, and postprocessor) of ANSYS are then effectively used.

\section{Conclusions}

A four-node composite facet-shell element is developed based on first-order shear deformation theory through a co-ordinate transformation of a plate element. The element warping is included further to correct its out-ofplane deformation to capture the shell behavior properly. Electro-mechanical coupling is introduced through a linear piezoelectric theory to idealize the macrocharacteristics of MFC actuators and PZT-5A sensors. The developed element is subsequently validated with quasi-static piezoelectric coupling experiment conducted on a cylindrical shell structure.

Modal control technique, IMSC, is applied to LQG control procedures and it has been extended to address the combination resonances control (SMSC) of shell vibrations. A cylindrical composite shell vibration control has been illustrated, where both simple resonance and combination resonances controls are demonstrated. It is observed that IMSC is best suited for modes that are quite separated from other neighborhood elastic modes, whereas SMSC technique appears to be more appropriate for modes, which may develop a strong coupling with adjacent/closely placed poles or modes of almost similar nature (2nd and 4th modes in the present case). The efficiency of directionally active MFC actuators is thus evaluated for their application in the geometrically curved aircraft composite panels.

\section{References}

[1] J. S. Bevan, "Piezoceramic actuator placement for acoustic control of panels," NASA/CR-2001-211265, 2001.

[2] A. Kovalovs, E. Barkanov, and S. Gluhihs, "Active control of structures using macro-fiber composite (MFC)," Journal of Physics: Conference Series, vol. 93, no. 1, Article ID 012034, 2007.

[3] J. J. Ro, C. C. Chien, T. Y. Wei, and S. J. Sun, "Flexural vibration control of the circular handlebars of a bicycle by using MFC actuators," Journal of Vibration and Control, vol. 13, no. 7, pp. 969-987, 2007.

[4] S. Varadarajan, K. Chandrashekara, and S. Agarwal, "Adaptive shape control of laminated composite plates using piezoelectric materials," AIAA Journal , pp. 197-205, 1996.

[5] A. Benjeddou, M. A. Trindade, and R. Ohayon, "A unified beam finite element model for extension and shear piezoelectric actuation mechanisms," Journal of Intelligent Material Systems and Structures, vol. 8, no. 12, pp. 1012-1025, 1997.

[6] D. A. Saravanos, "Mixed laminate theory and finite element for smart piezoelectric composite shell structures," AIAA Journal, vol. 35, no. 8, pp. 1327-1333, 1997.

[7] S. Raja, T. Ikeda, and D. Dwarakanathan, "Deflection and vibration control of laminated plates using extension and shear actuated fiber composites," Smart Materials Research, vol. 2011, Article ID 515942, 15 pages, 2011. 
[8] J. N. Reddy, "Exact solutions of moderately thick laminated shells," Journal of Engineering Mechanics, vol. 110, no. 5, pp. 794-809, 1984.

[9] V. Balamurugan and S. Narayanan, "Active vibration control of smart shells using distributed piezoelectric sensors and actuators," Smart Materials and Structures, vol. 10, no. 2, pp. 173-180, 2001.

[10] M. B. Xu and S. Gangbing, "Active vibration control of cylindrical shell using smart materials ," in Smart Structures and Materials: Smart Structures and Integrated Systems, vol. 4701 of Proceedings of SPIE, p. 518, San Diego, Calif, USA, 2002.

[11] S. P. Singh, H. S. Pruthi, and V. P. Agarwal, "Efficient modal control strategies for active control of vibrations," Journal of Sound and Vibration, vol. 262, no. 3, pp. 563-575, 2003.

[12] R. L. Clark and C. R. Fuller, "Active control of structurally radiated sound from an enclosed finite cylinder," in Proceedings of the Conference on Recent Advances in Active Control of Sound and Vibration, pp. 380-402, Virginia Polytechnic Institute and State University, Blacksburg, Va, USA, 1991.

[13] V. R. Sonti and J. D. Jones, "Dynamic effects of piezoactuators on the cylindrical shell response," AIAA Journal, vol. 34, no. 4, pp. 795-801, 1996.

[14] M. Bernadou and C. Haenel, "Modelization and numerical approximation of piezoelectric thin shells Part II: approximation by finite element methods and numerical experiments," Computer Methods in Applied Mechanics and Engineering, vol. 192, no. 37-38, pp. 4045-4073, 2003.

[15] M. K. Kwak, S. Heo, and M. Jeong, "Dynamic modelling and active vibration controller design for a cylindrical shell equipped with piezoelectric sensors and actuators," Journal of Sound and Vibration, vol. 321, no. 3-5, pp. 510-524, 2009.

[16] T. Roy and D. Chakraborty, "Optimal vibration control of smart fiber reinforced composite shell structures using improved genetic algorithm," Journal of Sound and Vibration, vol. 319, no. 1-2, pp. 15-40, 2009.

[17] J. W. Sohn and S.-B. Choi, "Optimal placements of MFC actuators for vibration control of cylindrical shell structure," Advances in Science and Technology, vol. 56, pp. 253-258, 2008.

[18] M. S. Azzouz, C. Mei, J. S. Bevan, and R. J. Jong, "Finite element modeling of MFC/AFC actuators and performance of MFC," Journal of Intelligent Material Systems and Structures, vol. 12, no. 9, pp. 601-612, 2001.

[19] E. J. Ruggiero, G. Park, and D. J. Inman, "Multi-input multioutput vibration testing of an inflatable torus," Mechanical Systems and Signal Processing, vol. 18, no. 5, pp. 1187-1201, 2004.

[20] B. P. Naganarayana and G. Prathap, "Force and moment corrections for the warped four-node quadrilateral plane shell element," Computers and Structures, vol. 33, no. 4, pp. 1107$1115,1989$. 

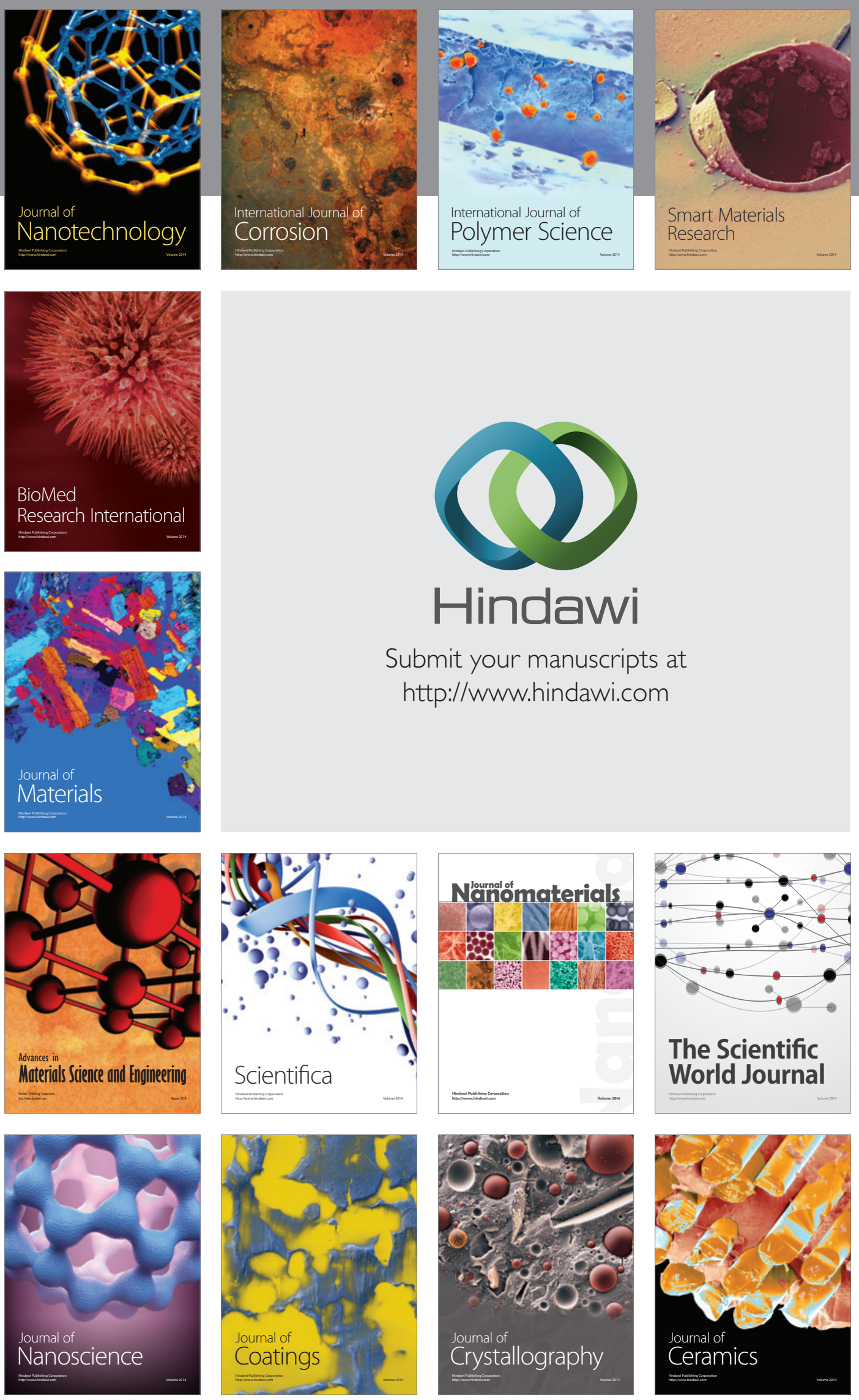

The Scientific World Journal

Submit your manuscripts at

http://www.hindawi.com

\section{World Journal}

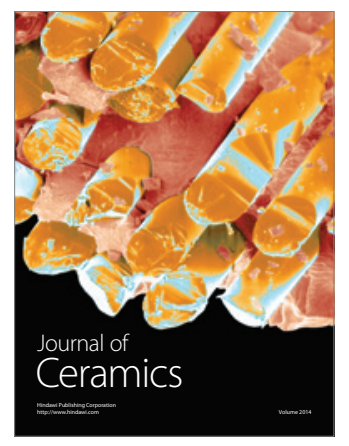

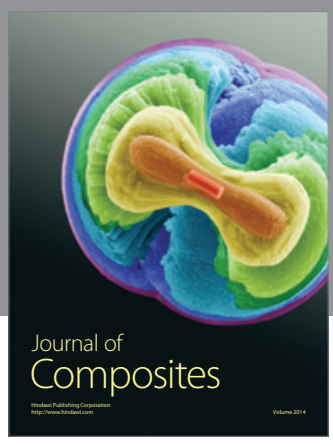
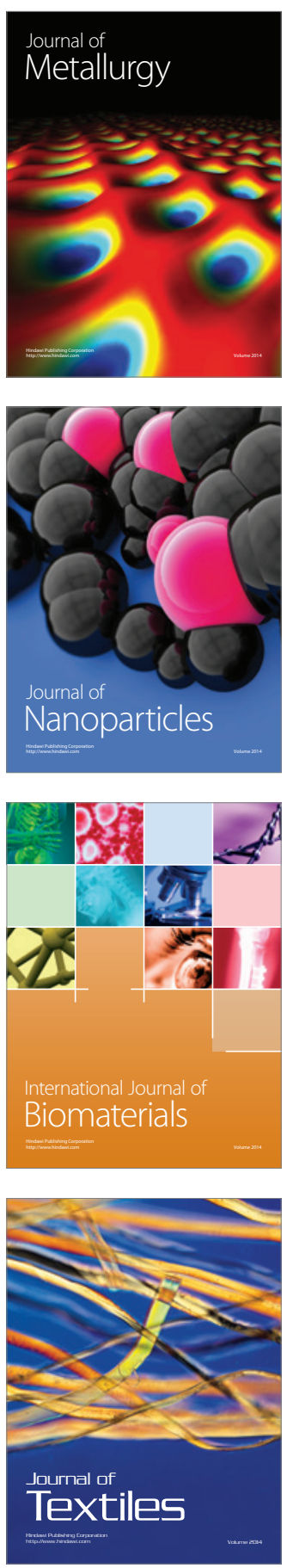